Gut, 1986, 27, 765-770

\title{
Disorganisation of intermediate filament structure in alcoholic and other liver diseases
}

\author{
C BARBATIS, J MORTON, J C WOODS, J BURNS, J BRADLEY, AND \\ J O'D McGEE \\ From the University of Oxford Nuffield Department of Pathology, John Radcliffe Hospital, Oxford
}

SUMmaRY The distribution of Mallory body antigens JMB1 and 2 was examined in 82 human fresh diagnostic needle liver biopsies and 28 necropsies by the indirect immunoperoxidase technique using 2 monoclonal antibodies (anti-JMB1 and 2) against Mallory bodies. The JMB1 antigen was detectable in bile duct epithelium and in hepatocytes of histologically normal livers. It was also found in all Mallory bodies in various hepatic disorders. This antigen was markedly increased in the cytoplasm of all liver cells in acute alcoholic hepatitis superimposed on alcoholic cirrhosis, in most cases of acute alcoholic hepatitis, and in severe fatty infiltration of the liver with or without Mallory body formation. Mallory bodies contained this antigen but the cytoplasm of Mallory body containing cells lacked JMB1. In normal liver the JMB2 antigen was localised on the cytoplasmic intermediate filament network of hepatocytes and bile duct epithelium; and almost all Mallory bodies also contained this antigen but the adjacent cytoplasm of these cells lacked JMB2. In severe alcoholic liver disease these antigens could not be detected in large zones of hepatocytes even when these hepatocytes did not contain Mallory bodies. It is evident that there is disorganisation of intermediate filament constituents in severe alcoholic liver disease.

Although there is a relationship between the severity of chronic liver disease and amount and duration of alcoholic consumption, only $20-30 \%$ of heavy drinkers develop cirrhosis. ${ }^{1}$ Each individual seems to respond differently to alcohol abuse and there is increased female susceptibility to cirrhosis. ${ }^{2}$ The factors predisposing to irreversible alcoholic liver damage may be multifactorial but alcoholic hepatitis is widely regarded as the forerunner of cirrhosis ${ }^{3-6}$; however, it has been suggested that perivenular sclerosis in alcoholic fatty liver in $\operatorname{man}^{7}$ and in the baboon is a precursor of cirrhosis. ${ }^{8}$

The hallmark of alcoholic liver disease is the formation of Mallory bodies in the cytoplasm of swollen hepatocytes. On light microscopy Mallory bodies appear as eosinophilic homogeneous or fibrillary masses in the cytoplasm of an almost empty hepatocyte. Ultrastructurally Mallory bodies are composed of filaments measuring 10-20 nm. Type I Mallory bodies consist of arrays of parallel

Address for correspondence: Professor J O'D McGee, Nuffield Dept of Pathology, John Radcliff Hospital, Level 1, Headington, Oxford OX3 9DU.

Received for publication 4 November 1985. filaments; Type II Mallory bodies consist of haphazardly arranged filaments and Type III Mallory bodies have in addition a granular electron dense amorphous core. ${ }^{9-11}$ There is evidence that Mallory bodies have a complex structure composed mainly of aggregated intermediate filaments; they react with antisera to prekeratins which are the main subunits of epithelial intermediate filaments ${ }^{12} 13$ and they possess non-prekeratin components detected with monoclonal antibodies to human Mallory body protein. ${ }^{14}$

Mallory bodies are not specific for alcoholic hepatitis and they can be detected in primary biliary cirrhosis, chronic cholestasis, Wilson's disease, jejuno-ileal bypass, advanced cirrhosis of any aetiology and Indian childhood cirrhosis. Other liver diseases and drugs or toxins can lead to Mallory body formation. ${ }^{11}$ Experimentally, Mallory bodies form after the administration of antitubulin agents such as griseofulvin ${ }^{15}$ and colchicine ${ }^{16}$; they also occur in diethyl nitrosamine induced hepatomas. ${ }^{17}$ With polyclonal antibodies it has been shown that there is antigenic similarity between the Mallory bodies of various liver diseases. ${ }^{18}$ Their chemotactic ability for polymorphs combined with their fib- 
rogenic properties and induction of cell mediated immunity have been regarded as important factors in the development of chronic liver disease. ${ }^{19} 2021$

In this study the distribution of Mallory body antigens, as defined by anti-JMB1 and anti-JMB2, ${ }^{14}$ in normality and liver diseases is reported.

\section{Methods}

\section{BIOPSIES}

Eighty two percutaneous needle diagnostic liver biopsies were collected at the time of biopsy, immediately frozen and stored in liquid nitrogen. Liver tissue from 28 necropsies (up to $28 \mathrm{~h}$ post mortem) was similarly handled. All cases were $\mathrm{HB}_{\mathrm{S}} \mathrm{Ag}$ seronegative by radioimmunoassay.

The mouse monoclonal antibodies anti-JMB1 and anti-JMB2 were produced by Morton et al ${ }^{14}$ by the technique of Kohler and Milstein. ${ }^{22}$ The anti-JMB1 antibody was used as undiluted culture fluid (IgG concentration $-6 \mu \mathrm{g} / \mathrm{ml}$ ) and as ascitic fluid diluted $1 / 1000$ in PBS (final IgG concentration $=40 \mu \mathrm{g} / \mathrm{ml}$ ). The anti-JMB2 culture fluid was used undiluted (IgG concentration $=4 \mu \mathrm{g} / \mathrm{ml}$ ).

Cryostat sections (4-6 $\mu \mathrm{m}$ thick) were air dried at $37^{\circ} \mathrm{C}$ for one hour, fixed in acetone at $-20^{\circ} \mathrm{C}$ for 15 minutes and dried at $22^{\circ} \mathrm{C}$. After washing in PBS for 10 minutes they were incubated with the appropriate monoclonal antibody for one hour at $22^{\circ} \mathrm{C}$, washed in PBS and treated with peroxidase conjugated antimouse IgG (Dakopatts, Copenhagen) diluted $1 / 60$ in PBS containing $1 \%(\mathrm{v} / \mathrm{v})$ normal human serum. They were then exposed to diaminobenzidine $/ \mathrm{H}_{2} \mathrm{O}_{2}$ for five minutes, counterstained with haematoxylin, dehydrated and mounted in DPX. Negative controls included: replacement of antiJMB antibodies with a mouse monoclonal anti-HLA (Class 1) antibody, $\mathrm{P} 2 \cdot 6^{23}$ and the peroxidase conjugated reagent alone.

\section{Results}

Using undiluted culture fluid as the source of the anti-JMB1 monoclonal antibody it was found that most normal livers (11 of 14) did not show detectable amounts of JMB1 antigen either in the bile ducts or hepatocytes as previously reported. ${ }^{14}$ In all cases, however, mouse ascitic fluid containing antiJMB1, showed a hepatocellular filamentous cytoplasmic network with cell and nuclear membrane distribution; bile duct epithelium also labelled with this antibody (Fig. 1). The discrepancy of results between culture and ascitic fluid was due to the lower IgG concentration in the culture fluid. The latter concentrated four times $(24 \mu \mathrm{g} / \mathrm{ml})$ gave staining intensity similar to the ascitic fluid. We conclude, therefore, that JMB1 antigen is also present in normal hepatocytes and bile ducts and has a similar distribution to the JMB2 antigen (see below). All further work was done, therefore, with ascitic fluid containing anti-JMB1. In all cases of severe acute alcoholic hepatitis, 'with or without' cirrhosis, JMB1 antigen was markedly increased in the non-MB containing hepatocytes (Fig. 2) and in the bile duct epithelium compared to normal livers (Table 1). Although Mallory bodies also contained JMB1 the adjacent cytoplasm of these cells lacked this antigen. In some cases of alcoholic cirrhosis without Mallory body formation small randomly distributed hepatocytes gave a strong reaction with anti-JMB1. A marked increase of the JMB1 antigen in hepatocytes also occurred in nonalcoholic liver disease usually associated with intra or extrahepatic cholestasis. In a variety of other liver diseases this antigen was also increased, particularly in those with proliferating bile ducts (Table 2). In one case of large duct obstruction and two cases of

Table 1 Hepatocellular JMB1 antigen in normality and alcoholic liver disease

\begin{tabular}{lccc}
\hline & & \multicolumn{2}{c}{ JMBI antigen } \\
\cline { 3 - 4 } Condition & $\begin{array}{l}\text { Cases } \\
\text { (no) }\end{array}$ & Increased & Present \\
\hline Normality* & 14 & 3 & 11 \\
Fatty infiltration & 9 & 3 & 6 \\
Fibrosis & 5 & 4 & 1 \\
Acute alcoholic hepatitis & 9 & 6 & $3^{+}$ \\
Cirrhosis & 1 & 0 & 1 \\
Cirrhosis/alcoholic hepatitis & 24 & 24 & 0 \\
\hline
\end{tabular}

*All of these livers were morphologically normal. The three cases which showed an apparent increase of JMB1 were from two sibs of a patient with primary haemochromatosis and the other was a patient who had a liver biopsy for staging of Hodgkin's disease. ${ }^{+}$Mild alcoholic hepatitis

Table 2 Hepatocellular JMB1 antigen distribution in non-alcoholic liver disease

\begin{tabular}{llll}
\hline & & \multicolumn{2}{l}{ JMBI antigen } \\
\cline { 4 - 4 } Condition & $\begin{array}{l}\text { Cases } \\
\text { (no) }\end{array}$ & Increased & Present \\
\hline Cholestatic liver* disease & & & \\
$\quad$ (non-PBC) & 10 & 6 & 4 \\
PBC & 7 & 3 & 4 \\
CAH & 3 & 1 & 2 \\
Acute viral hepatitis & 3 & 2 & 1 \\
Chronic persistent hepatitis & 1 & 0 & 1 \\
Granulomatous hepatitis & 5 & 0 & 5 \\
Cryptogenic cirrhosis & 3 & 2 & 1 \\
Fatty change & 2 & 2 & 0 \\
Miscellaneous & 12 & 2 & 10 \\
\end{tabular}

*This group comprised biopsies from cases of extrahepatic biliary disease and drug induced cholestasis. 

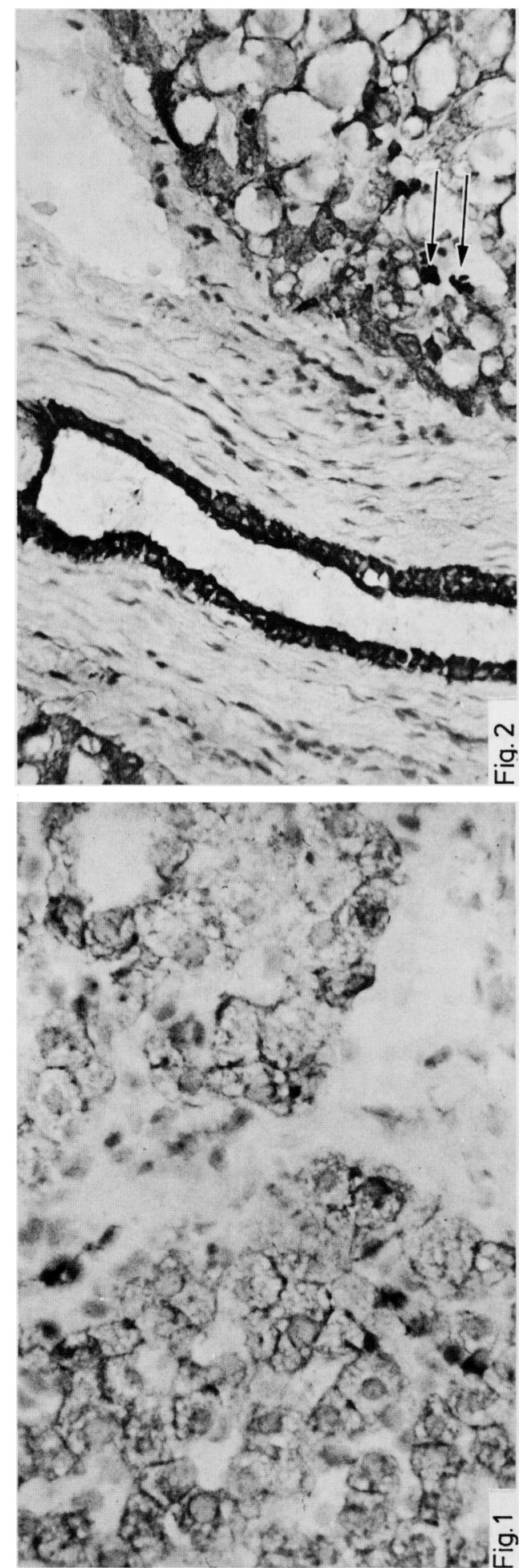
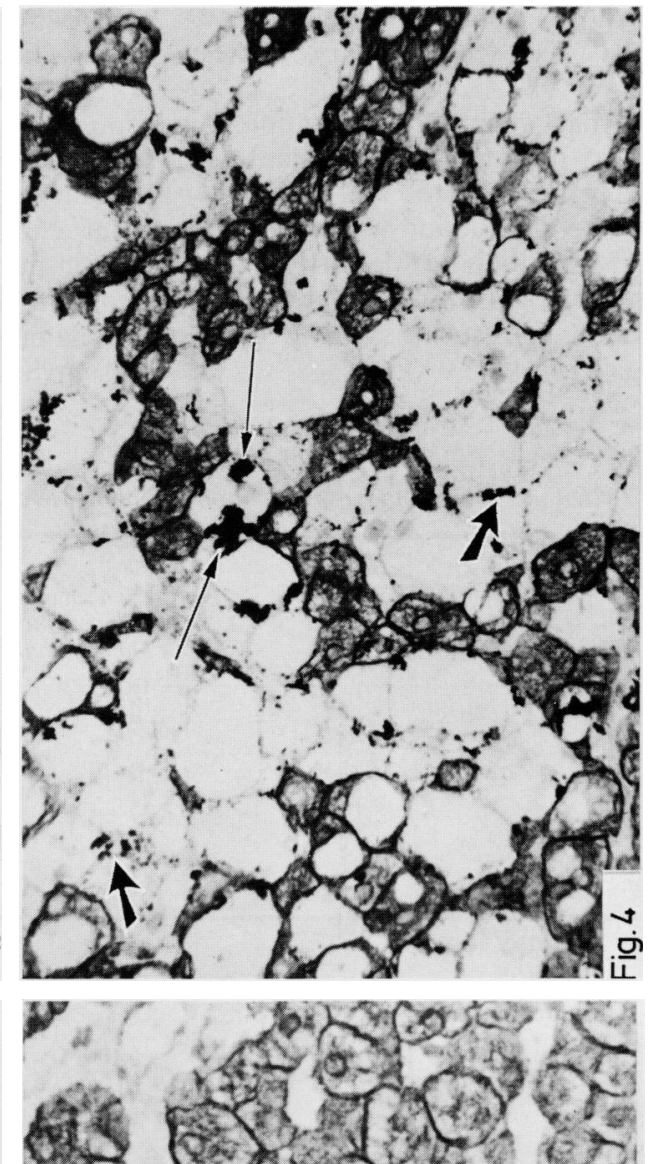

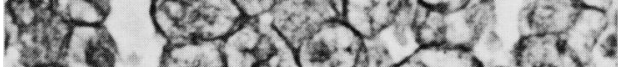
(x)

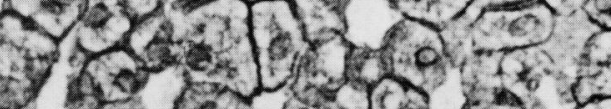

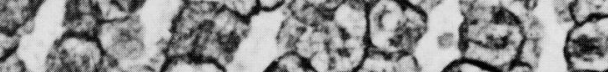

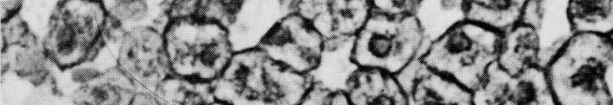

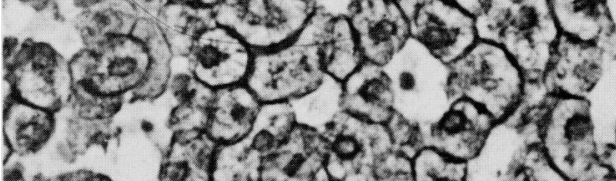

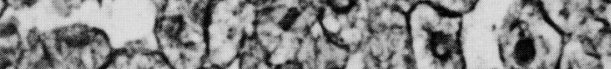

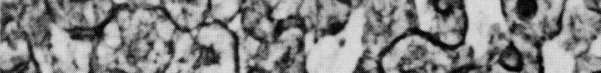
P. $3 x^{3}$ (12) 2.0.

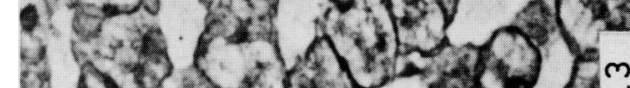

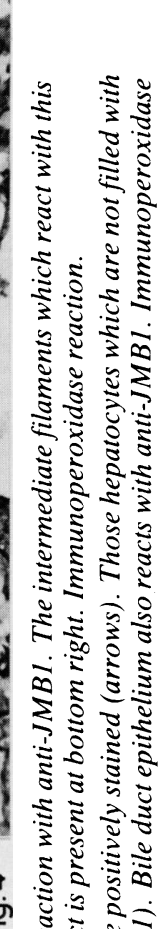

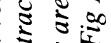

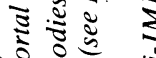

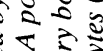

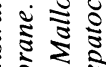
है ปิ วิ จ

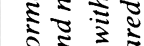

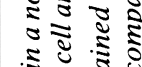
ปร कू ริ ปิ

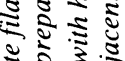

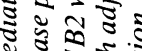

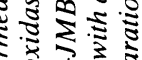

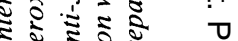

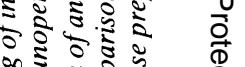

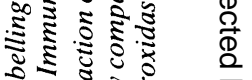

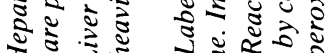

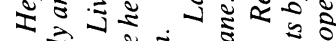
\% 吕 
primary biliary cirrhosis Mallory bodies were present; in all three cases the Mallory bodies contained JMB1.

The JMB2 antigen had a similar distribution to JMB1 in that it was present in a filamentous cytoplasmic network in hepatocytes and bile duct epithelium (Fig. 3). This distribution was markedly affected in hepatocytes containing Mallory bodies where the filamentous cytoplasmic component had disappeared with simultaneous strong staining of the Mallory bodies (Fig. 4).
In patients with severe alcoholic hepatitis with Mallory bodies but without cirrhosis confluent areas of the centrilobular region showed hepatocytes completely depleted of the JMB2 and JMB1 antigens even in the absence of Mallory bodies (Fig. 4). In some hepatocytes these antigens were detected as small clumps or granules distributed along the cytoplasmic membrane (Fig. 4). In some cases of alcoholic cirrhosis this marked disorganisation of the filamentous structure of hepatocytes was also present even in the absence of Mallory body

Table 3 Depletion of JMB1 and JMB2 antigens in alcoholic and other liver diseases

\begin{tabular}{lccccc}
\hline & & & Negative hepatocytes \\
\cline { 4 - 6 } Condition & $\begin{array}{l}\text { Cases } \\
\text { (no) }\end{array}$ & $\begin{array}{l}\text { No containing } \\
\text { Mallory bodies }\end{array}$ & Periportal & Confluent & $\begin{array}{c}\text { Centri- } \\
\text { lobular }\end{array}$ \\
\hline Alcoholic fatty infiltration & 9 & 0 & 0 & 0 & 0 \\
Alcoholic fibrosis & 5 & 0 & 0 & 0 & 0 \\
Acute alcoholic hepatitis & 9 & 8 & 0 & 0 & 0 \\
Cirrhosis/alcoholic hepatitis & 24 & 1 & 0 & 0 & 0 \\
Alcoholic cirrhosis/without hepatitis & 7 & 2 & 2 & 0 & 0 \\
PBC & 5 & 1 & 1 & 0 & 0 \\
Large bile duct obstruction & & & & 0 & 0 \\
\hline
\end{tabular}

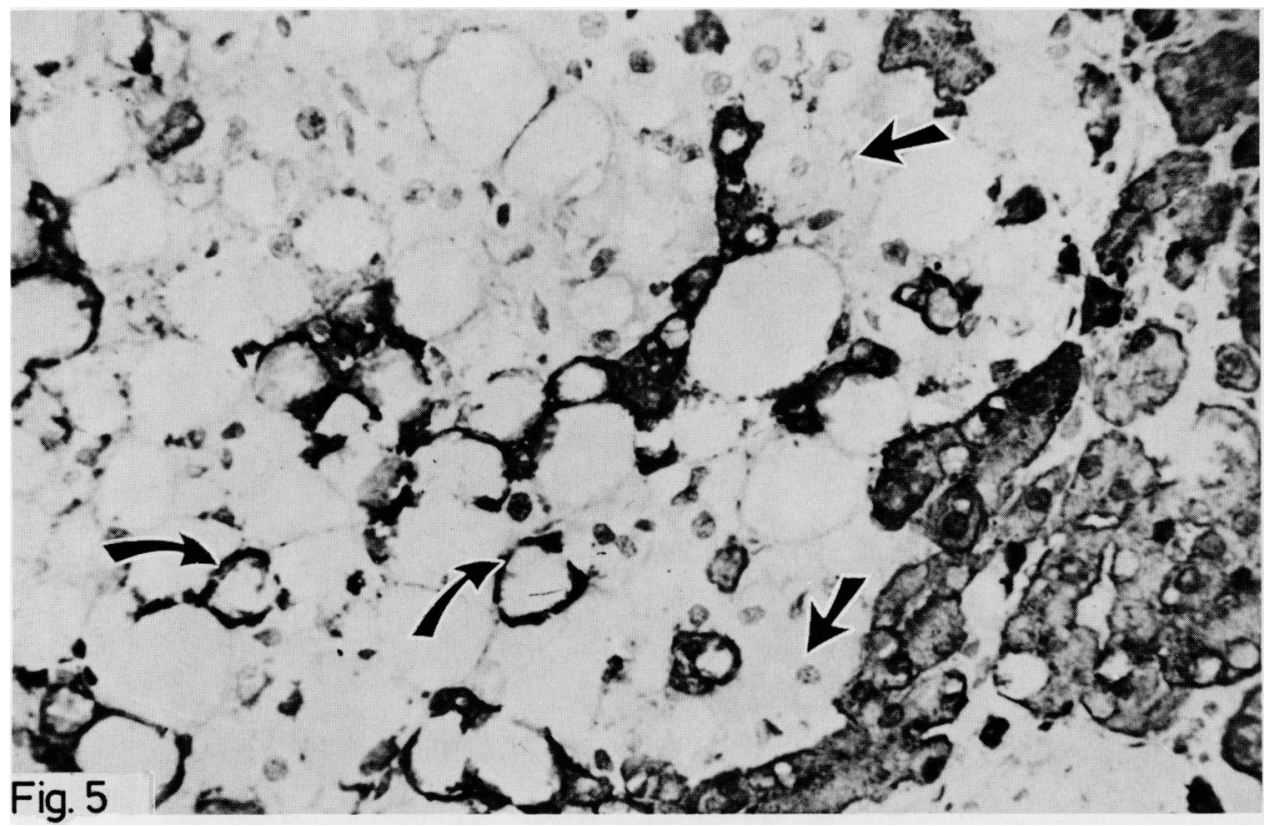

Fig. 5. Apparent loss of intermediate filaments from hepatocytes in the absence of Mallory body formation. In this cirrhotic liver the majority of the hepatocytes do not have detectable quantities of JMB2 antigen (arrows). Small aggregates of Mallory body material are evident in some cells (curved arrows). Immunoperoxidase reaction with anti-JMB2. 
formation (Fig. 5). In mild alcoholic hepatitis only groups, or single hepatocytes, of the centrilobular region were depleted of both antigens.

Mallory bodies present in two cases of primary biliary cirrhosis and in one case of large duct obstruction stained with JMB1 and JMB2. The cytoplasm of these Mallory body containing cells also showed depletion of the antigens recognised by both monoclonal antibodies. Depletion of JMB1 and 2 from hepatocytes were not observed in the other 34 cases of liver disease studied.

\section{Discussion}

The cytoskeleton of every eukaryotic cell comprises microfilaments (mean diameter $=6 \mathrm{~nm}$ ) containing actin, intermediate filaments (mean diameter $=10$ $\mathrm{nm}$ ) and microtubules (mean diameter $=22 \mathrm{~nm}$ ) composed of tubulin. ${ }^{24}$ It has been shown that alcohol has an anti-microtubular effect ${ }^{25-26}$ which leads to inhibition of protein secretion and swelling of the cytoplasm of hepatocytes which is commonly observed in alcoholic liver disease. Treatment of rats with compounds having antitubulin activity (such as griseofulvin ${ }^{15}$ and colchicine ${ }^{16}$ ) result in the appearance of Mallory bodies which are identical to alcoholic hyaline. It has also been suggested that microtubular dissolution is followed by aggregation and increase in intermediate filaments.

Mallory bodies and a filamentous component in human hepatocytes also react with antiprekeratin antibodies and it is known that keratins are prominent subunits of epithelial intermediate filaments. ${ }^{13}$ Previous work in this laboratory has shown that the anti-JMB1 and JMB2 antibodies do not react with human keratin of the epidermis indicating the presence of non-prekeratin antigenic determinants in Mallory bodies and in the normal hepatocyte cytoskeleton. With the immunoperoxidase technique on chimp liver cells it was shown that antiJMB1 and anti-JMB2 antibody was localised on intermediate filaments and that these filaments whorled when the cells were treated with colchicine. ${ }^{28}$ This indicates that anti-JMB2 does not react with a cytokeratin since the latter do not whorl in colchicine treated cells.

It has been previously reported that JMB1 antigen was a unique determinant present only in Mallory bodies. ${ }^{14}{ }^{28}$ In this investigation, however, using the immunoperoxidase method which is at least 15 times more sensitive than immunoflourescence it is shown that the cytoskeleton of normal hepatocytes and bile duct epithelium express this antigen. Its marked increase in alcoholic and other liver diseases could be explained on the basis of enhanced production, decreased degradation or altered aggregation of
JMB1 antigen. The distribution of both JMB1 and 2 antigens in normality and liver disease is similar and this suggests that both antigens are expressed on the intermediate filaments of hepatocytes and bile ducts.

The antigenic similarity of Mallory bodies in alcoholic liver disease, primary biliary cirrhosis and chronic large bile duct obstruction ${ }^{18}$ has been confirmed in this study using monoclonal instead of polyclonal antibodies to Mallory bodies.

The markedly altered distribution of both antigens with a predilection for centrilobular hepatocytes in alcoholic hepatitis indicate that alcohol affects the metabolism of the intermediate filaments directly by an unknown mechanism or indirectly because of its antimicrotubular affect. ${ }^{25} 26$

Whatever the mechanism of disorganisation of intermediate filament structure it is probable that this could have a profound effect on normal protein production. It has recently been shown that the intermediate filament system of Hela and other cells contain messenger RNA and also CAP binding protein. ${ }^{29}{ }^{30}$ The latter facilitates the translation of mRNA. It is postulated therefore, that disorganisation of intermediate filaments in hepatocytes of alcoholic liver disease leads to disruption of the protein synthesising systems of those cells and consequent cell death.

\section{References}

1 Popper $\mathrm{H}$. The pathogenesis of alcoholic cirrhosis. In: Fisher MM, Rankin JG eds. Alcohol and the liver. New York: Plenum Press, 1976: 289-307.

2 Morgan MY, Sherlock S. Sex related differences among 100 patents with alcoholic liver disease. $\mathrm{Br} \mathrm{Med}$ J 1977; 1: 939-41.

3 Edmondson HA, Peters RL, Frankel HH, Borowsky S. The early stage of liver injury in the alcoholic. Medicine 1967; 46: 119-29.

4 Lischner MW, Alexander JF, Galambos JT. Natural history of alcoholic hepatitis. I. The acute disease. Am J Dig Dis 1971; 16: 481-94.

5 Galambos J. Natural history of alcoholic hepatitis III. Histological changes. Gastroenterology 1972; 63: 102635.

6 Helman RA, Jemko HM, Nye SW, Fallon HJ. Alcoholic hepatitis: natural history and evolution of predione therapy: Ann Intern Med 1971; 74: 646-50.

7 van Waes L, Lieber CS. Early perivenular sclerosis in alcoholic fatty liver: an index of progressive liver injury. Gastroenterology, 1977; 73: 646-50.

8 Popper H, Leiber CS. Histogenesis of alcoholic fibrosis and cirrhosis in the Baboon. Am J Pathol 1980; 98: 695-709.

9 Wiggers KD, French SW, French BA, Carr BN. The ultrastructure of Mallory body filaments. Lab Invest 1973; 29: 652-8. 
10 Rumpelt HJ. Ultrastructure of alcoholic hyalin and fate of the affected hepatocytes. Virchows Arch B [Cell Pathol] 1977; 23: 339-51.

11 French SW. The Mallory body structure, composition and pathogenesis. Hepatology 1981; 1: 76-83.

12 Denk H, Franke WW, Eckerstorfer R, Schmid E, Kerjaschki D. Formation and involution of Mallory bodies ("alcoholic hyalin") in murine and human liver revealed by immunofluorescence microscopy with antibodies to prekaratin. Proc Natl Acad Sci USA 1979; 76: 4112-6.

13 Denk H, Franke WW, Dragosics B, Zeiler J. Pathology of cytoskeleton of liver cells. Demonstration of mallory bodies (alcoholic hyaline) in murine and human hepatocytes by immunofluorescence microscopy using antibodies to cytokeratin polypeptides from Hepatocytes. Hepatology 1981; 1: 9-20.

14 Morton JA, Bastin J, Fleming KA, McMichael A, Burns J, McGee J O'D. Mallory bodies in alcoholic liver disease: identification of cytoplasmic filament/cell membrane and unique antigenic determinants by monoclonal antibodies. Gut 1981; 22: 1-7.

15 Denk H, Gschnait F, Wolff K. Hepatocellular hyalin (Mallory bodies) in the mouse. Lab Invest 1977; 36: 563-5.

16 Denk H, Eckerstorfer R. Colchicine-induced Mallory body formation in the mouse. Lab Invest 1977; 36: 563-5.

17 Borenfreund E, Higgins PJ, Peterson E. Intermediate sized filaments in cultured rat liver tumour cells with Mallory-like cytoplasm abnormalities; JNCI 1980; 64: 323-8.

18 Fleming KA, Morton JA, Barbatis C, Burns J, Canning $\mathrm{S}$, McGee J O'D. Mallory bodies in alcoholic and non-alcoholic liver disease contain a common antigenic determinant. Gut 1981; 22: 985-91.

19 Sorrell M, Leevy CM. Lymphocyte transformation and alcoholic liver injury. Gastroenterology 1972; 63: 1020-5.

20 Leevy CM, Chen T, Luisada-Opper A, Kanagasundaram N, Zetterman R. Liver disease of the alcoholic: role of immunologic abnormalities in pathogenesis, recognition and treatment. In: Popper $\mathrm{H}$, Schaffner $\mathrm{F}$. Eds. Progress in liver diseases. New York: Grune and Stratton, 1976; 51: 6-30.

21 Zetterman RK, Luisada-Opper A, Leevy CM. Alcoholic Hepatitis: cell mediated immunologic response to alcoholic hyaline. Gastroenterology 1976; 70: 382-4.

22 Kohler G, Milstein C. Continuous cultures of Fused cells secreting antibody t predefined specificity. Nature 1975; 256: 495-7.

23 Brodsky FM, Parham P, Barnstable CJ, Crumpton MJ, Bodmer WF. Monoclonal antibodies for analysis of the HLA system. Immunol Rev 1979; 47: 3-61.

24 Lazarides E. Intermediate filaments as mechanical integrators of cellular space. Nature 1980; 283: 249-56.

25 Baraona E, Leo MA, Borowsky SA, Lieber CS. Pathogenesis of alcohol-induced accumulation of protein in the liver. J Clin Invest 1977; 60: 546-54.

26 Matsuda Y, Baraona E, Salaspuro M, Lieber CS. Effects of ethanol on liver microtubules and Golgi apparatus. Possible role in altered hepatic secretion of plasma proteins. Lab Invest 1979; 41: 455-63.

27 De Brabanter M, Aerts F, Van de Viere R, Borgers M. Evidence against interconversion of microtubules and filaments. Nature 1979; 253: 119-20.

28 McGee J O'D, Morton JA, Barbatis C, Bradley JF, Fleming KA, Goate AM, Burns J. Monoclonal antibodies to Mallory bodies/intermediate filaments, and HLA (Class I) antigens in human liver disease. In: McMichael AJ, Fabre JW eds. Monoclonal antibodies in clinical medicine. New York: Academic Press, 1982: 431-55.

29 Zumbi L, Stahli C, Trachsel H. Association of $\mathrm{M}$ 50000 cap-binding protein with the cytoskeleton in baby hamster kidney cells. Proc Natl Acad Sci 1982; 79: 2927-31.

30 Shatkin A, Darzynkiewicz E, Furuichi Y, et al. $S^{\prime}$-Terminal caps, cap-binding proteins and eukaryotic $m R N A$ Function in Messenger RNA and ribosomes in protein synthesis. London: The Biochemical Society, $1982 ; 129-43$. 